\title{
Sulfur Polymer Stabilization/Solidification (SPSS) Treatability of Simulated Mixed-Waste Mercury Contaminated Sludge
}

J.W. Adams, B.S. Bowerman, and P.D. Kalb

October 2001

\section{BROOKHRUEN NATIONAL LABORATORY}

Environmental Sciences Department

Brookhaven National Laboratory

Brookhaven Science Associates

Upton, Long Island, New York 11973

Under Contract No. DE-AC02-98CH10886 with the

UNITED STATES DEPARTMENT OF ENERGY 



\section{DISCLAIMER}

This report was prepared as an account of work sponsored by an agency of the United States Government. Neither the United State Government nor any agency thereof, nor any of their employees, not any of their contractors, subcontractors, or their employees, makes any warranty, express or implied, or assumes any legal liability or responsibility for the accuracy, completeness, or usefulness of any information, apparatus, product, or process disclosed, or represents that its use would not infringe privately owned rights. Reference herein to any specific commercial product, process, or service by trade name, trademark, manufacturer, or otherwise, does not necessarily constitute or imply its endorsement, recommendation, or favoring by the United States Government or any agency, contractor, or subcontractor thereof. The views and opinions of authors expressed herein do not necessarily state or reflect those of the United States Government or any agency, contractor or subcontractor thereof. 


\title{
Sulfur Polymer Stabilization/Solidification (SPSS) Treatability of Simulated Mixed-Waste Mercury Contaminated Sludge
}

\author{
J.W. Adams, B.S. Bowerman, and P.D. Kalb
}

October 2001

\author{
Work Conducted for \\ U.S. Department of Energy \\ Office of Science and Technology \\ Mixed Waste Focus Area
}

\author{
Work Conducted by \\ Environmental Research and Technology Division \\ Department of Environmental Science \\ Brookhaven National Laboratory \\ Upton, NY 11973
}





\begin{abstract}
The Environmental Protection Agency (EPA) is currently seeking to validate technologies that can directly treat radioactively contaminated high mercury $(\mathrm{Hg})$ subcategory wastes without removing the mercury from the waste. The Sulfur Polymer Stabilization/Solidification (SPSS) process developed at Brookhaven National Laboratory is one of several candidate technologies capable of successfully treating various $\mathrm{Hg}$ waste streams. To supplement previously supplied data on treatment of soils, EPA needs additional data concerning stabilization of high $\mathrm{Hg}$ subcategory waste sludges. To this end, a 5000 ppm sludge surrogate, containing approximately $50 \mathrm{wt} \%$ water, was successfully treated by pilot-scale SPSS processing. In two process runs, 85 and $95 \mathrm{wt} \%$ of water was recovered from the sludge during processing. At waste loadings of $30 \mathrm{wt} \%$ dry sludge, the treated waste form had no detectable mercury $(<10 \mathrm{ppb})$ in TCLP leachates. Data gathered from the demonstration of treatment of this sludge will provide EPA with information to support revisions to current treatment requirements for high $\mathrm{Hg}$ subcategory wastes.
\end{abstract}


TABLE OF CONTENTS

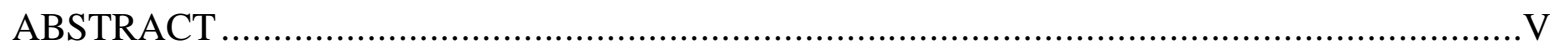

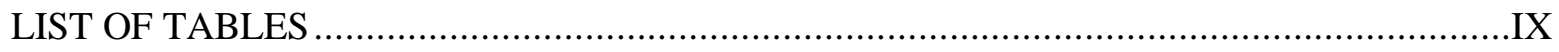

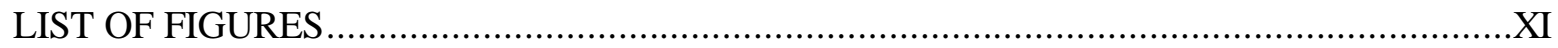

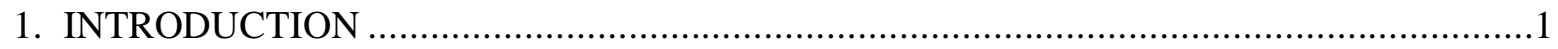

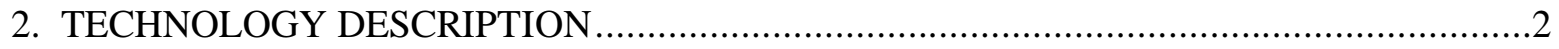

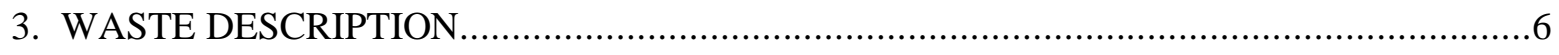

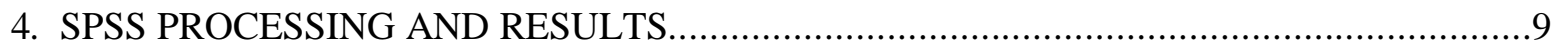

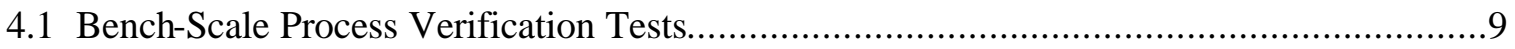

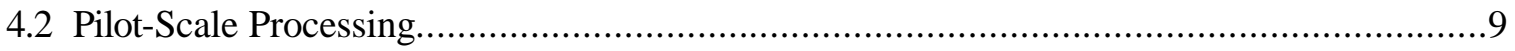

4.3 TCLP Qualification of SPSS Processed MER04 Sludge Surrogate Waste .........................17

5. TECHNICAL AND ECONOMIC CONSIDERATIONS ........................................... 18

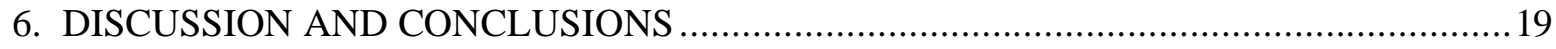

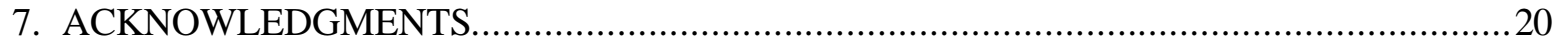

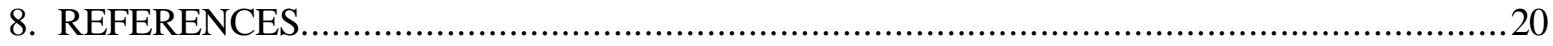




\section{LIST OF TABLES}

Table 1. MER04 Sludge Surrogate Formulation............................................................. 6

Table 2. SPSS Batch Compositions For Pilot-Scale MER04 Sludge Surrogate Treatment.............10 


\section{LIST OF FIGURES}

Figure 1 SPSS Vertical Cone Mixer and Process Controls............................................. 4

Figure 2 SPSS Off-GasTreatment Components..................................................... 5

Figure 3 MER04 Sludge Surrogate Preparation........................................................... 8

Figure 4 MER04 Sludge Surrogate Prior to SPSS Treatment................................................ 8

Figure 5 Inside View of Vertical Cone Mixer................................................................... 11

Figure 6 Powdered SPC Added to Vertical Cone Mixer....................................................... 11

Figure 7 MER04 Sludge With Partial Quantity of Powdered SPC...................................... 12

Figure 8 MER04 Sludge With Partial SPC, After 5 min Mixing. .......................................... 12

Figure 9 MER04 Sludge, After Adding Balance of Powdered SPC .................................. 13

Figure 10 MER04 Sludge With Balance of SPC, After 5 min Mixing................................. 13

Figure 11 MER04 Sludge/SPC Mixture, After Partial Addition of $\mathrm{Na}_{2} \mathrm{~S}$. .............................. 14

Figure 12 MER04 Sludge/SPC Mixture, After Complete Addition of $\mathrm{Na}_{2} \mathrm{~S}$............................. 14

Figure 13 SPSS Reacted MER04 Sludge, After Partial Dewatering................................... 16

Figure 14 SPSS Reacted MER04 Sludge, After Complete Dewatering................................ 16

Figure 15 Preparation of TCLP Pellets from SPSS Treated MER04 Sludge............................ 17

Figure 16 SPSS Treated MER04 Sludge Cast as 8mm Diameter Pellets................................ 18 


\section{INTRODUCTION}

This study extends the application of Sulfur Polymer Stabilization/Solidification (SPSS) to treatment of high mercury $(\mathrm{Hg})$ subcategory waste, i.e., a simulated mercury sludge waste containing $>260 \mathrm{ppm} \mathrm{Hg}$. In the SPSS process, elemental mercury or mercury-containing wastes are reacted with powdered sulfur polymer cement (a thermoplastic material composed of $95 \mathrm{wt} \%$ elemental sulfur) to form a stable mercury sulfide compound with significantly reduced leachability and for elemental mercury lower vapor pressure. The reacted mixture is then melted, mixed, and cooled to form a monolithic solid waste form in which the stabilized mercury particles are microencapsulated within a sulfur polymer matrix.

The Environmental Protection Agency's (EPA) Land Disposal Restrictions (LDR) program currently has technology-specific treatment standards for hazardous wastes containing greater than orequal to 260 ppm total mercury (Hg) (i.e. high $\mathrm{Hg}$ subcategory wastes). The treatment standards specify RMERC for high $\mathrm{Hg}$ subcategory wastes and IMERC if the high $\mathrm{Hg}$ subcategory wastes contain organics. RMERC requires retorting or roasting in a thermal processing unit, while IMERC specifies incineration. Both of these standards are based on the premise of recovering the $\mathrm{Hg}$ for recycling. In the case of radioactively contaminated wastes, the recovered $\mathrm{Hg}$ is typically still radioactively contaminated, and therefore cannot be recycled. EPA requires that this recovered, radioactively-contaminated $\mathrm{Hg}$ undergo additional treatment, specifically amalgamation, prior to disposal. The Department of Energy (DOE) TRU and Mixed Waste Focus Area (TMFA) and the Mercury Working Group (HgWG) chartered under the TMFA, are working with EPA to validate technologies that can directly treat radioactivelycontaminated high $\mathrm{Hg}$ subcategory wastes without removing the mercury from the waste.

To date under this program, a waste soil from Brookhaven National Laboratory (BNL) containing approximately 4,800 ppm of $\mathrm{Hg}$ and radioactive contaminants has been successfully treated by several different vendors to meet a $\mathrm{Hg}$ Toxic Characteristic Leaching Procedure (TCLP) treatment goal of $0.025 \mathrm{mg} / \mathrm{l}$ or less. These treated waste forms are now undergoing several additional evaluations at the University of Cincinnati (UC) and Oak Ridge National Laboratory (ORNL), using new analytical protocols developed by faculty at Vanderbilt University and UC. These new protocols provide another methodology to determine how the treated waste form will behave in a variety of disposal environments.

To supplement the soil treatment results, BNL and several commercial technology vendors will provide additional data for stabilization of high $\mathrm{Hg}$ subcategory waste sludges under this program. The data gathered from this treatability study for simulated mixed waste mercury contaminated sludge will assist EPA in their decision to revise current LDR regulations and allow alternative treatment technologies, such as stabilization, of high $\mathrm{Hg}$ subcategory wastes.

As in the demonstration on the BNL soils referenced above, this effort has two major objectives. The first is to evaluate stabilization as an alternative process to RMERC and IMERC for DOE's legacy mixed waste. To that end, the process will treat a high $\mathrm{Hg}$ subcategory surrogate waste to achieve a TCLP treatment goal of $0.025 \mathrm{mg} / \mathrm{l}$ or less. The second objective is to provide EPA with treated waste forms so that EPA can compare the proposed new analytical protocols to standard TCLP results. EPA will use these comparisons in their efforts to revise the LDR treatment standards for Hgbearing hazardous wastes. 
The Scope Of Work (SOW) for this project involved the following steps:

1. Preparation of samples for subsequent testing by UC and ORNL. Sludge surrogate components (except water) were supplied by UC in sufficient quantity for one $50 \mathrm{lb}$ batch. The sludge was prepared at BNL.

2. Lab-scale process tests were conducted to verify a solidification/stabilization formulation. An acceptable formulation was one that had less than $0.025 \mathrm{mg} / \mathrm{L} \mathrm{Hg}$ in leachate, as determined by TCLP.

3. A large batch without mercury was prepared and the lab-scale formulation was used to verify pilot-scale operating parameters.

4. The surrogate sludge (containing $5,000 \mathrm{ppm} \mathrm{Hg}$ ) was sampled per work scope specifications.

5. A large, pilot-scale batch of the surrogate sludge was treated using the BNL SPSS technology. A sample was sent to an independent lab for TCLP testing.

6. Following positive $(<0.025 \mathrm{mg} / \mathrm{L} \mathrm{Hg})$ TCLP results, samples of treated surrogate sludge and before-treatment sludge were shipped to UC and ORNL per work scope specifications.

These steps are described in detail below.

\section{TECHNOLOGY DESCRIPTION}

Sulfur Polymer Stabilization/Solidification (SPSS) is based on Sulfur Polymer Microencapsulation, a patented mixed-waste treatment technology previously developed at BNL. ${ }^{1}$ Sulfur Polymer Cement (SPC) consists of $95 \mathrm{wt} \%$ elemental sulfur reacted with $5 \mathrm{wt} \%$ of an organic modifier to enhance mechanical integrity and long-term durability. Prior testing conducted on sulfur polymer waste forms indicates excellent performance under anticipated disposal conditions. ${ }^{2,3}$ During FY97, SPSS was developed at BNL as part of a DOE Mixed Waste Focus Area (MWFA) Quick Win Project, and used to treat $24.5 \mathrm{~kg}$ of BNL mixed-waste elemental mercury. ${ }^{4}$ In FY98, SPSS was demonstrated as a pilotscale process, successfully treating two 55 gallon drums of mixed waste $\mathrm{Hg}$ contaminated soils and $68 \mathrm{~kg}$ of mixed waste elemental $\mathrm{Hg}$, excavated from the BNL Chemical Holes. ${ }^{5}$ Newmont Mining, Inc. recently licensed SPSS for production-scale use on elemental $\mathrm{Hg}$ generated in gold mining operations.

SPSS mercury treatment (patent pending) is conducted in two stages. The first step is a reaction between mercury and powdered SPC, forming mercuric sulfide, as seen in Equation 1:

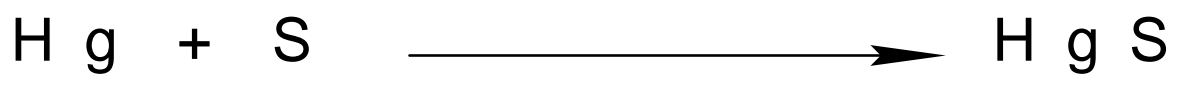

The second step involves melting the thermoplastic sulfur binder. On cooling, the reacted sulfide particles become microencapsulated within the inert sulfur matrix. Since the BNL SPSS process includes chemical stabilization of the mercury-yielding mercury sulfide, it meets EPA requirements for amalgamation, AMLGM. 
Bench-scale development work for the SPSS process demonstrated that as much as $33 \mathrm{wt} \%$ elemental mercury could be successfully encapsulated. Even at this waste loading, the final waste form still meets EPA TCLP leaching criteria. ${ }^{6}$ This ratio assures nearly a 12 -fold molar excess of sulfur to mercury, facilitating a fast reaction of the mercury metal with sulfur. A small quantity (up to $2 \mathrm{wt} \%$ ) of additive is included to ensure the sulfide reaction. During reaction the vessel is placed under inert gas (nitrogen) atmosphere to prevent the formation of mercuric oxide (a water soluble and highly leachable compound); also, the vessel is heated to $\sim 40^{\circ} \mathrm{C}$ to enhance sulfide formation. Once the mercury is chemically stabilized, the mixture is heated at about $130^{\circ} \mathrm{C}$ until a homogeneous molten mixture is formed. It is then poured into a suitable mold where it cools to form a monolithic solid waste form.

Pilot-scale SPSS processing was accomplished using a $1 \mathrm{ft}^{3}$, oil-heated, vertical cone mixer (Ross Mixers, Hauppauge, NY). Mixing action is provided by a 24-inch long auger screw, rotating up to 105 revolutions per minute (rpm), which also revolves orbitally around the wall of the vessel, at up to $2.5 \mathrm{rpm}$. Feed materials are charged to the unit through a 6-inch diameter port on the cone lid with the auger screw drawing material upward from the base of the cone. A photograph of the mixer and process control equipment is shown in Figure 1. When mixing or drying, the system may be evacuated to up to 22 " $\mathrm{Hg}$, or purged with an inert gas by connection to a regulated nitrogen gas supply. Heat is provided to the jacketed cone by a $9 \mathrm{~kW}$ circulating fluid heat transfer system (Mokon, Buffalo, NY). A $5 \mathrm{~cm}$ ( 2 in) heated ball valve at the base of the cone is used to discharge the molten SPSS product.

Off gas is captured in multiple stages: first it passes through a shell and tube heat exchanger cooled by a 3 ton chiller (Mokon), followed by a liquid nitrogen cryogenic trap and finally through HEPA and activated charcoal filters before venting to the atmosphere. Condensate is collected for analyses at the heat exchanger in an off-gas condensate vessel and at the cryogenic trap. A photograph of the off-gas system components is shown in Figure 2. 


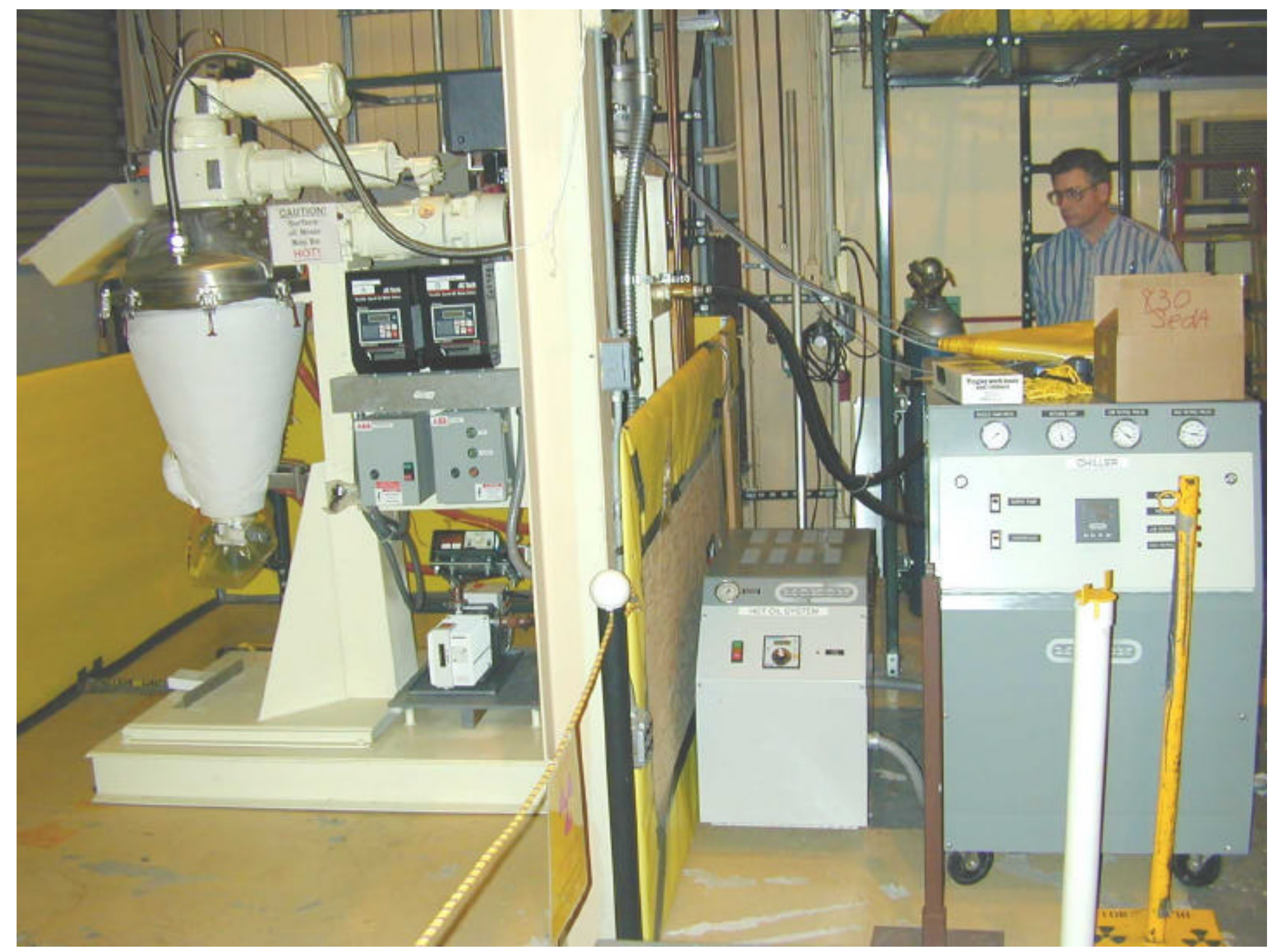

Figure 1 SPSS Vertical Cone Mixer and Process Controls. 


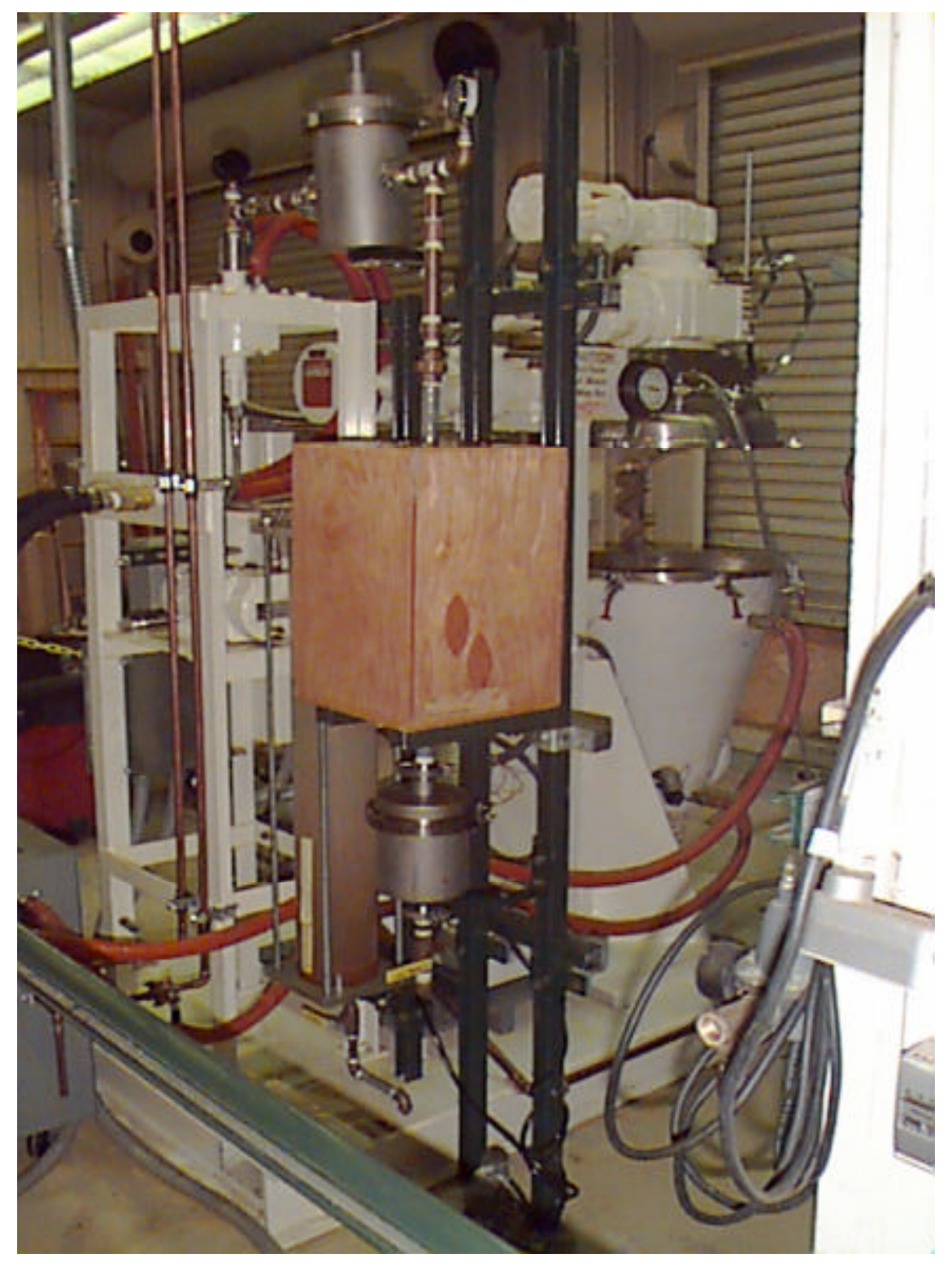

Figure 2 SPSS Off-Gas Treatment Components. 


\section{WASTE DESCRIPTION}

The waste to be treated was a sludge surrogate containing 5,000 ppm of mercury, in the form of elemental mercury $(0.15 \mathrm{wt} \%)$, phenyl-mercuric chloride $(0.05 \mathrm{wt} \%)$, and mercuric oxide, mercuric nitrate, and mercuric chloride $(0.10 \mathrm{wt} \%$ each). Four inorganic compounds comprised the bulk of solids in the sludge: diatomaceous earth (20 wt $\%$ ), and aluminum hydroxide, ferric chloride, and sodium chloride (10 wt $\%$ each). The remaining $49.5 \mathrm{wt} \%$ of the sludge weight was water. Each component was individually pre-packaged for surrogate consistency at the ALTER Facility of the University of Cincinnati (UC). (UC is conducting stabilization technology evaluations for EPA.) At BNL, gross and net weights of these compounds were verified prior to their addition to the appropriate quantity of water.

Two batches, $50 \mathrm{lb}$ each, were prepared, as given in Table 1. The first lot, containing mercury compounds, was used for bench-scale formulation verification tests and final pilot-scale demonstration. The second batch, prepared without mercury contaminants, was used for initial pilot-scale processing to determine mixing characteristics, corrosivity effects, and dewatering parameters in the Ross mixer system.

For each batch, inorganic chemicals were added to de-ionized water in a 45 liter polyethylene container. (Approximately 3 liters of water were kept separate prior to mixing, to use as rinse water, where needed.) The soluble salts (first $\mathrm{FeCl}_{3} \cdot 6 \mathrm{H}_{2} \mathrm{O}$, then $\mathrm{NaCl}$ ) were dissolved in de-ionized water, followed by addition of the insoluble compounds, $\mathrm{Al}(\mathrm{OH})_{3}$ and diatomaceous earth. A vertically-mounted commercial coring drill motor was used to turn a steel mixing blade (double-fluted, approximately 12" diameter x 6" high). The sludge thickened significantly after approximately? of the diatomaceous earth was added, requiring slow addition of the remainder. Approximately 15 minutes were required to complete addition of the four major constituents, after which the batches were stirred another 15 minutes to ensure homogenization. Batch 1 continued to be stirred an additional 15 minutes while the 5 mercury compounds were added. Figures 3 and 4 show photographs of the sludge during preparation. There was no visible difference between the mercury-loaded and nonhazardous batches. The sludge was very corrosive however, as evidenced by its severe attack on the mixing blade. The $\mathrm{pH}$ of the sludge was measured to be 0.98 .

Two 1-Liter samples of the mercury-spiked sludge surrogate were collected for bench-scale process experiments, approximately 5 hours after addition of the mercury compounds. Pre-treatment grab sampling, per the SOW, was done several weeks later, just prior to pilot-scale processing. In both cases the sludge was mixed for a minimum of 15 minutes to ensure homogeneity, and was then pumped using a peristaltic pump from the $50 \mathrm{lb}$ batch as it was being mixed. For UC and ORNL grab samples, approximately $100 \mathrm{ml}$ aliquots were pumped and transferred to 1 liter widemouth polyethylene bottles. This process was repeated 5 times to make up the approximately $500 \mathrm{gm}$ sample required for ORNL, and 10 times to make up the 1,000 gm sample required for UC. 
Table 1 MER04 Sludge Surrogate Formulation.

\begin{tabular}{|l|r|r|r|}
\hline & Nominal & \multicolumn{1}{|c|}{ Batch 1 } & Batch 2 \\
\hline Component & Wt. \% & \multicolumn{1}{c|}{ Net Wt. } & Net Wt. \\
\hline & & \multicolumn{1}{c|}{ gm } & \multicolumn{1}{c|}{ gm } \\
\hline Mercury Elemental & & & \\
\hline Phenyl-mercuric chloride III & 0.15 & 34.11 & \\
\hline Mercuric Nitrate II & 0.05 & & \\
\hline Mercuric Oxide /II & 0.1 & & \\
\hline Mercuric Chloride & 0.1 & 113.01 & \\
\hline & 0.1 & & \\
\hline Diatomaceous Earth - Bag 1 & & & \\
\hline & 20.0 & 4507.7 & 4540.0 \\
\hline & & 1355.8 & \\
\hline & & 454.1 & \\
\hline Aluminum Hydroxide - Bag 1 & & 1358.3 & \\
\hline & 10.0 & 2266 & 2270.0 \\
\hline Ferric Chloride & & 906.2 & \\
\hline & 10.0 & 2261.2 & 2270.0 \\
\hline Sodium Chloride & & & \\
\hline & 10.0 & 2265.1 & 2270.0 \\
\hline & 49.5 & $10,888.5$ & 11202.0 \\
\hline & & 3600.1 & \\
\hline Total sludge wt & & 3777.8 & \\
\hline
\end{tabular}




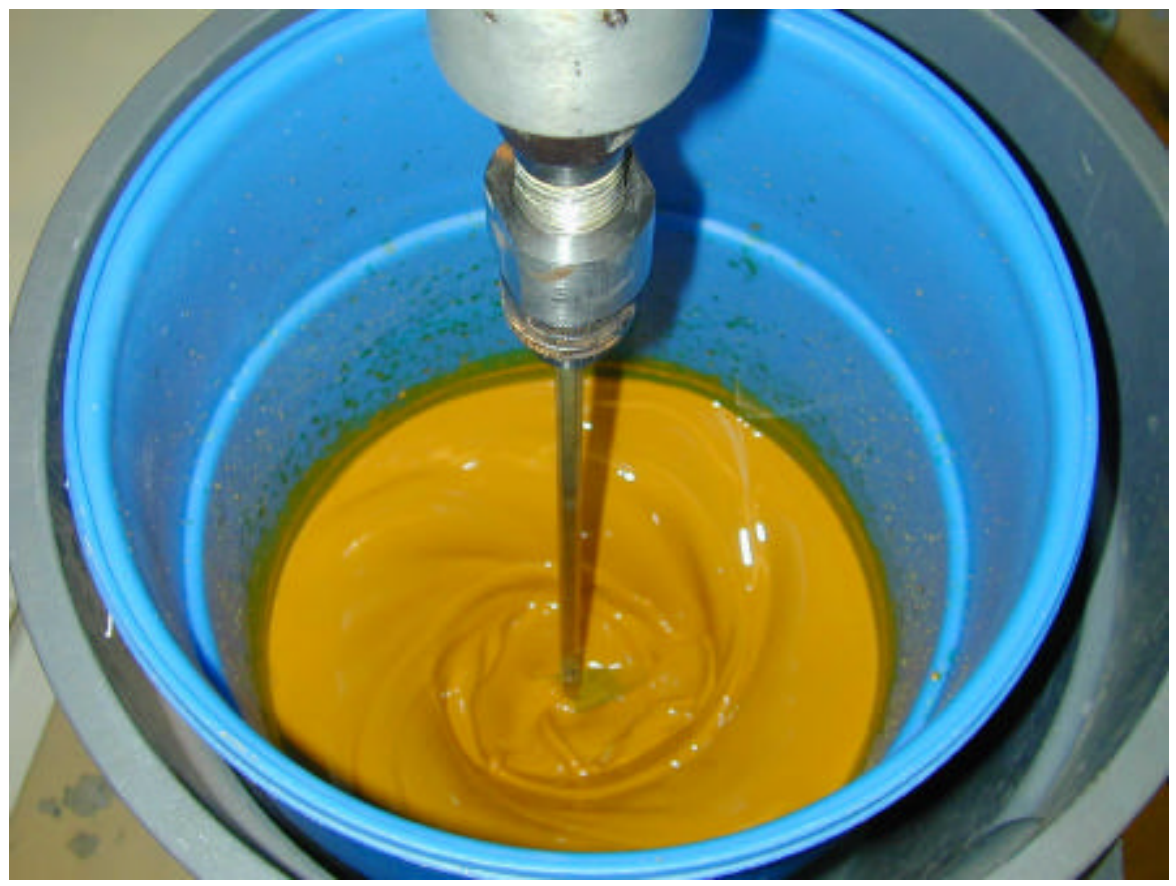

Figure 3 MER04 Sludge Surrogate Preparation.

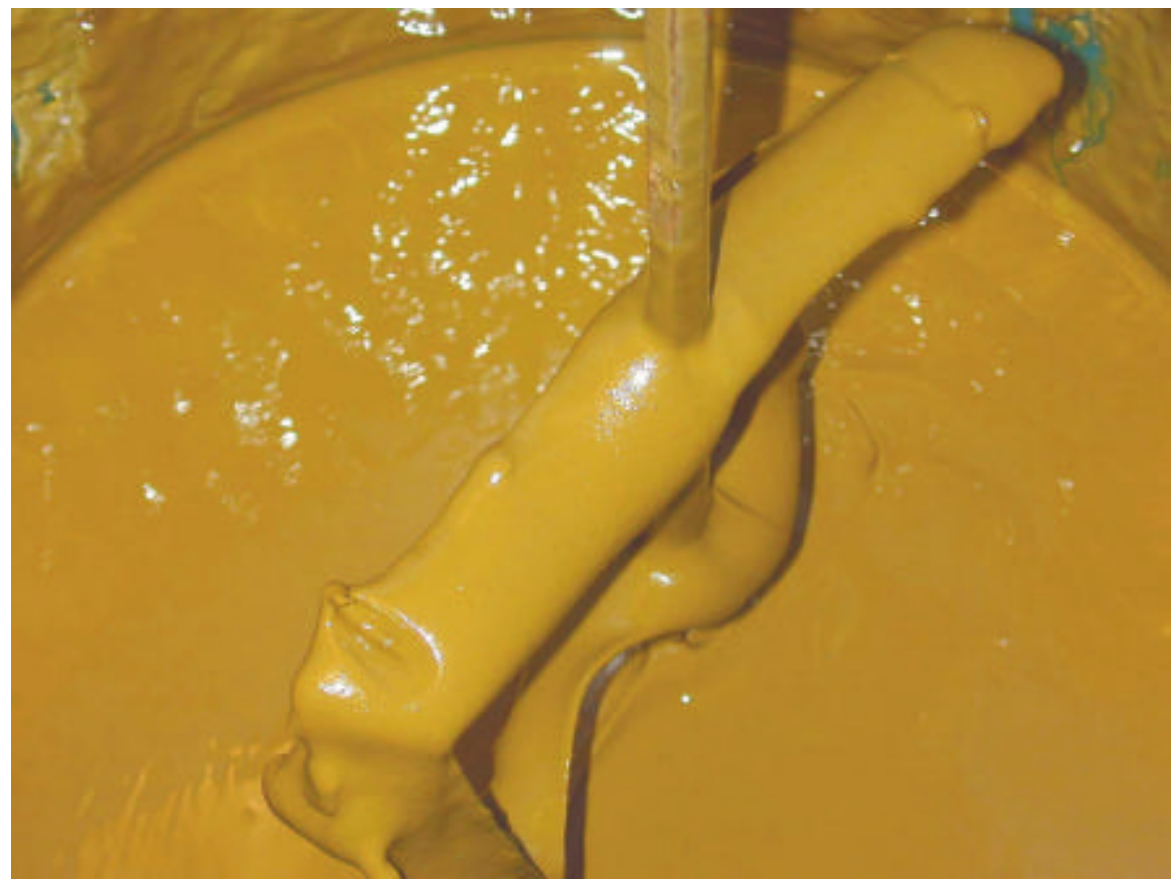

Figure 4 MER04 Sludge Surrogate Prior to SPSS Treatment. 


\section{SPSS PROCESSING AND RESULTS}

\subsection{Bench-Scale Process Verification Tests}

A series of bench-scale tests were carried out to establish waste loading limits for pilot-scale SPSS processing and the effect of additives on TCLP leachability. Optimal waste loading was determined by preparing test batches using one of the two 1-Liter grab samples of the previously prepared hazardous sludge surrogate. Initial batches were prepared at waste loadings of $70 \mathrm{wt} \%$ dry surrogate, the maximum loading identified in soil stabilization with SPSS. Batches were reacted with powdered sulfur polymer cement (SPC), then heated to remove water from the sludge. Bench-scale processing involved treating maximum $200 \mathrm{gm}$ batches in a Rotovap distillation apparatus, trapping the evaporated condensate to assure that no mercury was lost during drying. Once dry, the batch was heated to melt free SPC in the mixture, thereby microencapsulating the reacted sludge powder. Due to the fine particle size of this surrogate however, the $70 \mathrm{wt} \%$ mixture could not be wetted/encapsulated. Thus, increments of SPC powder were added until the mixture became fluid. While mixtures started to become workable with hand mixing at about $45 \mathrm{wt} \%$ dry surrogate, batches were not fluid enough to use an electric mixer until diluted to $<35 \mathrm{wt} \%$ waste loading. An optimal process formulation of $30 \mathrm{wt} \%$ dry surrogate was recommended for pilot-scale processing based on product workability.

After the workability of the molten mixture was determined, bench-scale tests were conducted to determine optimal use of additives, namely, sodium sulfide, to reduce mercury leachability in the final waste form. As sulfur in the additive reacts not only with mercury, but all readily soluble cations in the aqueous sludge, three formulations were prepared containing one half, one, and two-times the stoichiometric amount of sulfide calculated for the batch. The stoichiometric quantity was based on the total mercury plus total iron in ferric chloride. TCLP results of $30 \mathrm{wt} \%$ dry surrogate waste forms containing 1.49, 4.47 and $5.96 \mathrm{wt} \%$ sodium sulfide (hydrated form used for bench scale testing, 65.7 $\mathrm{wt} \% \mathrm{Na}_{2} \mathrm{~S}$ ) showed decreasing amounts of mercury in the leachates, approximately 500, 40, and $10 \mathrm{ppb}$, respectively. To meet the current UTS leachability limit for mercury, sodium sulfide addition of twice the calculated stoichiometric mass ( $6 \mathrm{wt} \%$ of the final waste form) was recommended for the pilot-scale formulation.

\subsection{Pilot-Scale Processing}

Using formulations derived in the bench-scale tests, BNL conducted pilot-scale treatment of MER04 sludge surrogate using the vertical cone mixer described earlier. Two batches were processed as previously noted, the first without mercury compounds and the second with. The first batch formulation was based on processing $40 \mathrm{lb}$ of wet sludge surrogate (actual sludge added was $18.44 \mathrm{~kg}$, or $40.66 \mathrm{lb}$ ). The second batch contained slightly less sludge surrogate, $15.88 \mathrm{~kg}(35 \mathrm{lb})$ due to surrogate material removed for bench-scale testing and pre-treatment grab sampling, per the SOW. The amount of $\mathrm{Na}_{2} \mathrm{~S}$ also varied slightly for the two batches, $4 \mathrm{wt} \%$ for the first versus $6 \mathrm{wt} \%$ (two times the calculated stoichiometric amount required) for the second, since the first batch was primarily intended to address processing issues. Compositions of the two process batches are given in Table 2. 
Table 2 SPSS Batch Compositions for Pilot-Scale MER04 Sludge Surrogate Treatment.

\begin{tabular}{|c|c|c|c|c|}
\hline & \multicolumn{2}{|l|}{ Batch 1 - No Mercury } & \multicolumn{2}{l|}{ Batch 2 - 5000 ppm Mercury } \\
\hline & Net Weight (gm) & Weight Percent** & Net Weight (gm) & Weight Percent \\
\hline Sludge Surrogate & 18,444 & & 15,876 & \\
\hline Solids* & 9,283 & 30.0 & 8,136 & 30.0 \\
\hline Water* & 9,161 & & 7,739 & \\
\hline Powdered SPC & 20,422 & 66.0 & 17,368 & 64.0 \\
\hline $\mathrm{Na}_{2} \mathrm{~S}$ (anhydrous) & 1,238 & 4.0 & 1,617 & 6.0 \\
\hline Total (wet basis) & 40,104 & & 34,861 & \\
\hline Total (dry basis) & 30,943 & 100.0 & 27,122 & 100.0 \\
\hline
\end{tabular}

*Calculated Quantities, Based on Weights Given in Table 1.

**Based on Final (Dewatered) SPSS Product.

Procedures developed during mercury-contaminated soil treatability studies were followed, namely with regards to addition and mixing of SPSS components, heating to remove water from the process batch, and melting of SPC to microencapsulate the stabilized sulfide compounds. Reaction time for this mixture was significantly reduced however, due to the aqueous sludge medium; 15 minutes of mixing was considered adequate to complete the sulfide reaction. Off-gas controls and worker industrial hygiene (mercury vapor) monitoring ensured containment of vapors during processing. Although the mixer container and screw are made of 316 stainless steel, all surfaces potentially in contact with the sludge were first coated with a layer of neat (molten) SPC to act as a protective barrier and also to "lubricate" the walls to enhance melting and discharge of the SPSS product (Figure 5).

The following procedures for adding, mixing and heating materials in the vertical cone mixer were used for both batches. With both screw and orbital drives on, approximately? to $3 / 4$ of the required powdered SPC was added to the mixer (Figure 6) via the 6" port on the bell of the cone. Wet sludge surrogate, in approximately $4 \mathrm{~kg}$ aliquots, was then added to the dry SPC, creating a pasty mustard-colored mix (Figure 7), which became significantly more fluid with increased mixing time (Figure 8). The remainder of the SPC was then added, forming an even dryer mix than before (Figure 9), which became more fluid as it mixed (Figure 10). (If all SPC had been added initially, the mix would have become too lumpy and sticky, with a tendency to pull material above the top of the screw where it could potentially interfere with the orbital action of the mixer.) After approximately 30 minutes of mixing, the batch had apparently reached a stable consistency. At this point $\mathrm{Na}_{2} \mathrm{~S}$ (anhydrous) was added, instantly changing the color of the batch from yellow to black as the powder contacted the sludge (Figure 11). On completion of $\mathrm{Na}_{2} \mathrm{~S}$ addition, the batch had turned completely black in color (Figure 12), the mixture once again thickened, and an immediate exotherm to about $30{ }^{\circ} \mathrm{C}$ was noted. The system was sealed by replacing the gasketed window to the 6" port, and the chamber pumped to $220^{\prime \prime}$ vacuum to evacuate air from the system. 


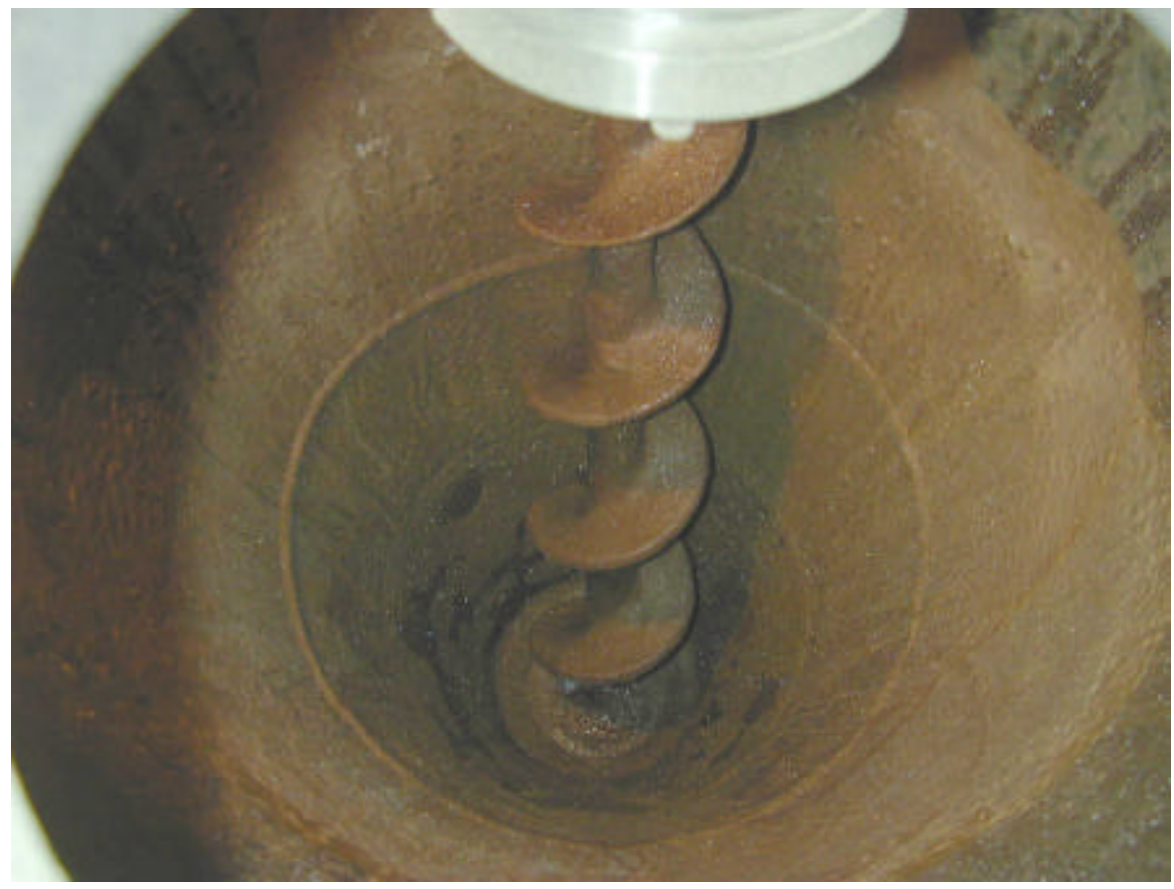

Figure 5 Inside View of Vertical Cone Mixer.

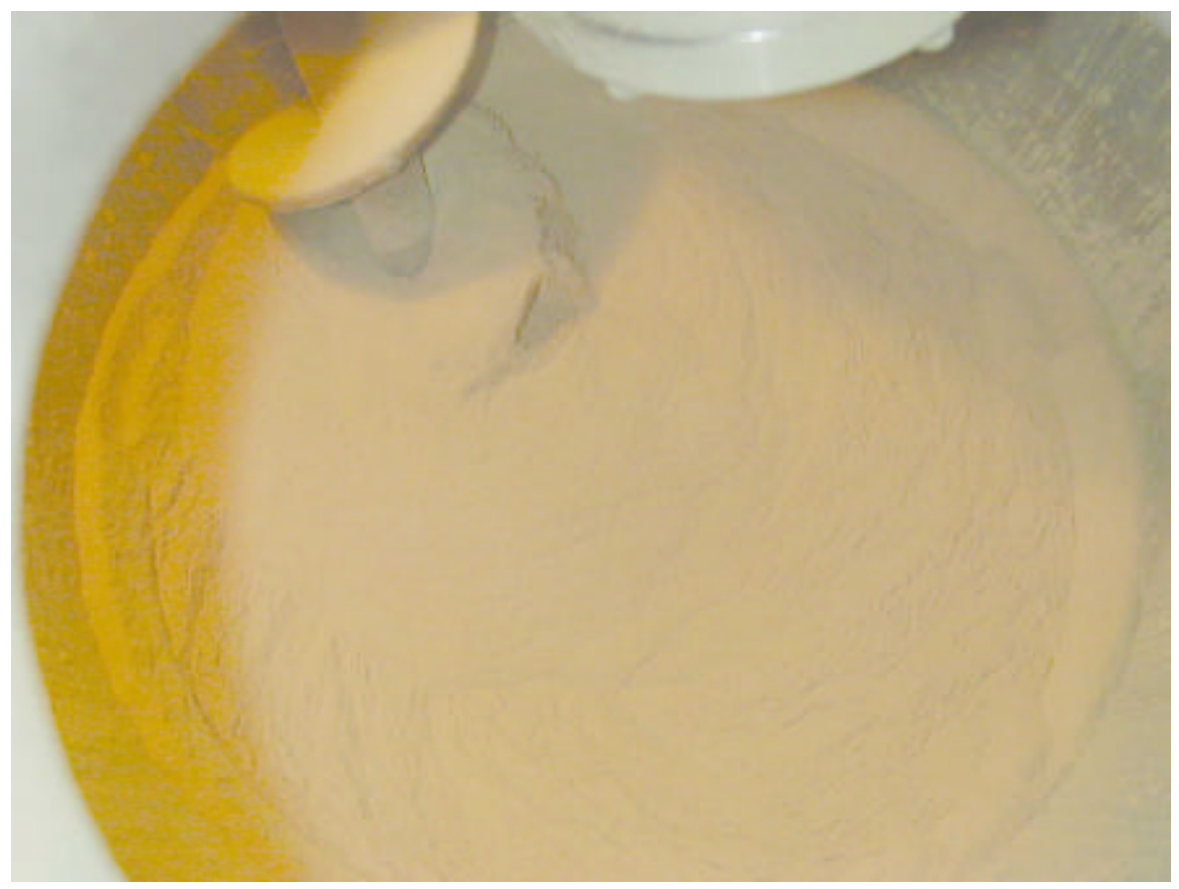

Figure 6 Powdered SPC Added to Vertical Cone Mixer. 


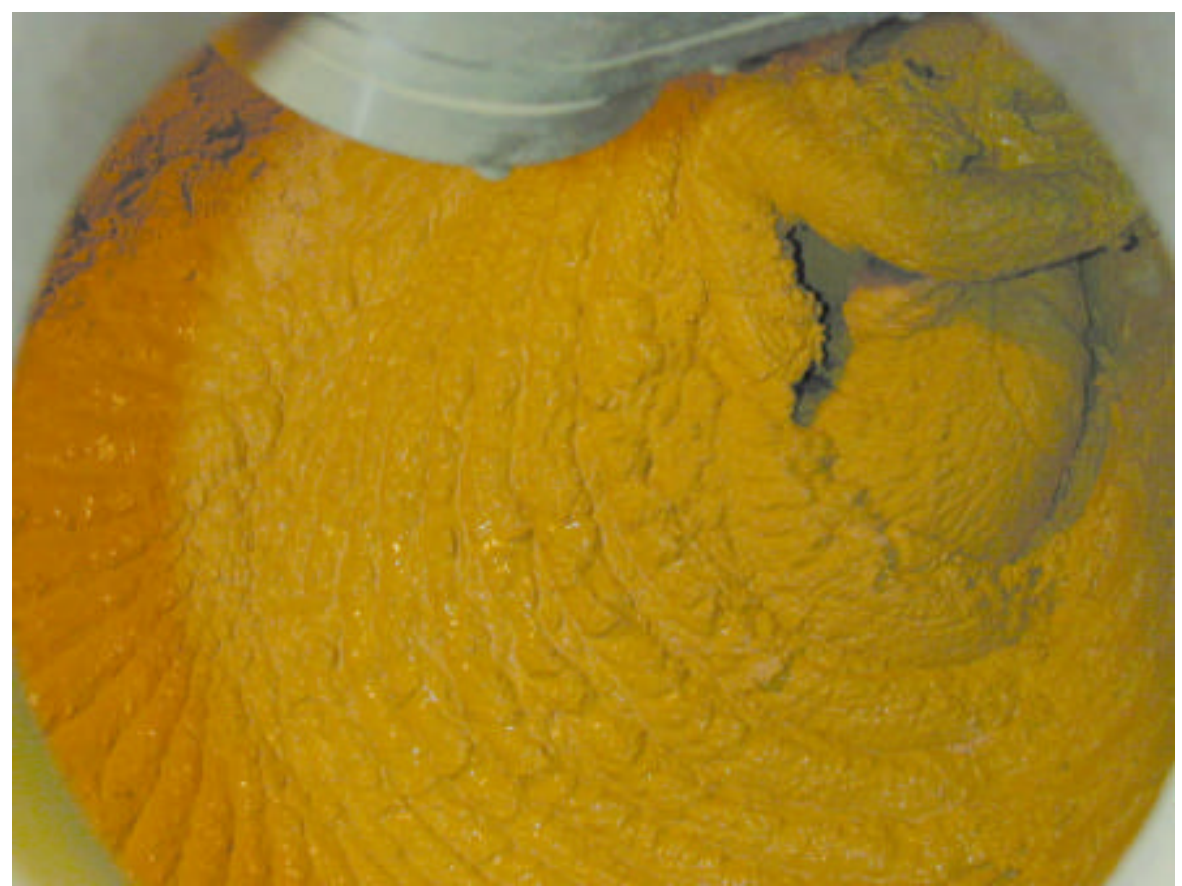

Figure 7 MER04 Sludge With Partial Quantity of Powdered SPC.

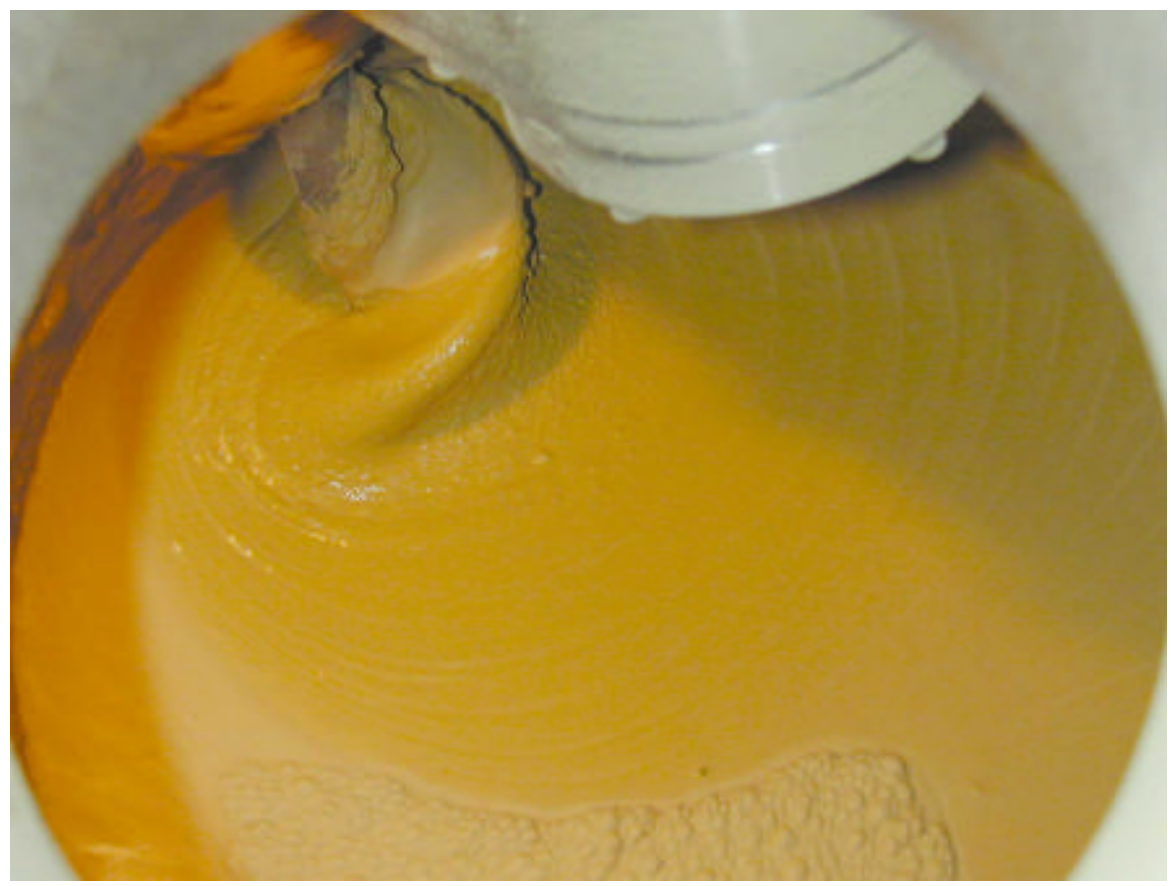

Figure 8 MER04 Sludge With Partial SPC, After 5 min Mixing. 


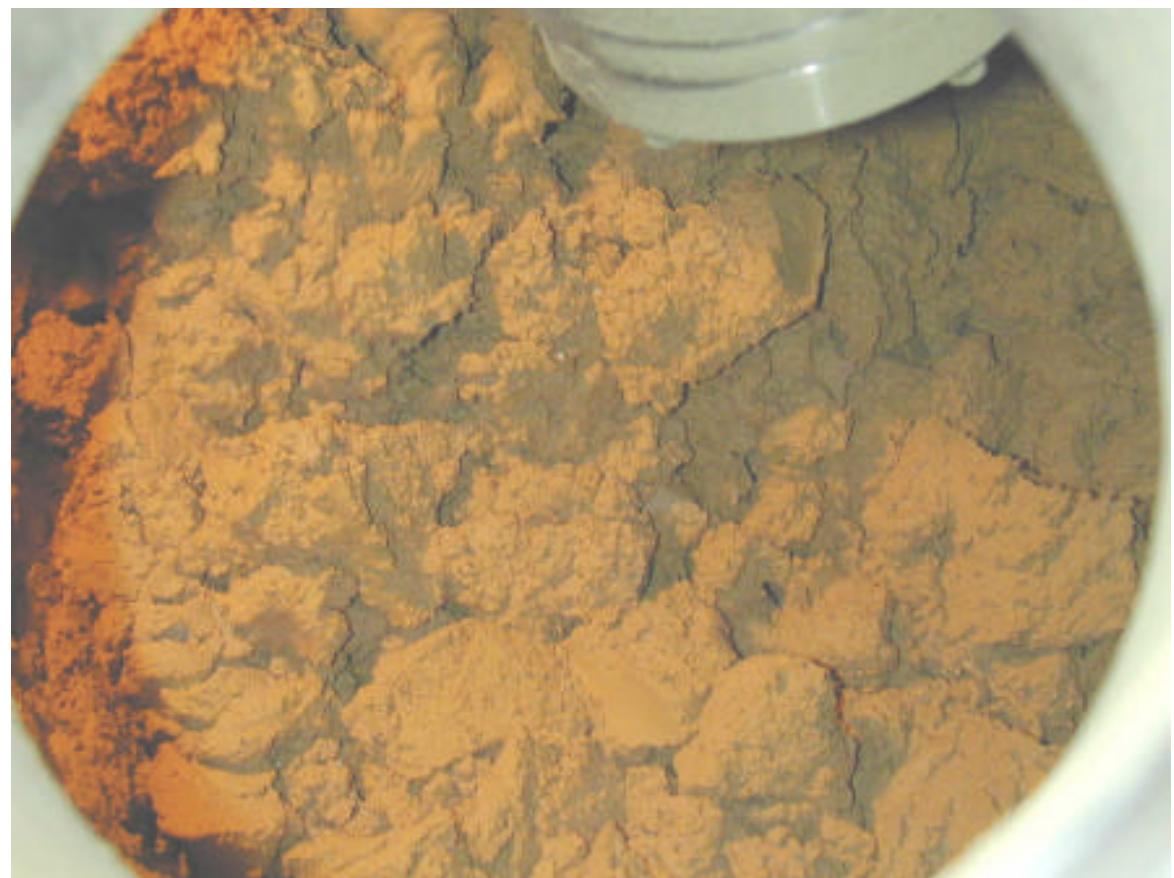

Figure 9 MER04 Sludge, After Adding Balance of Powdered SPC.

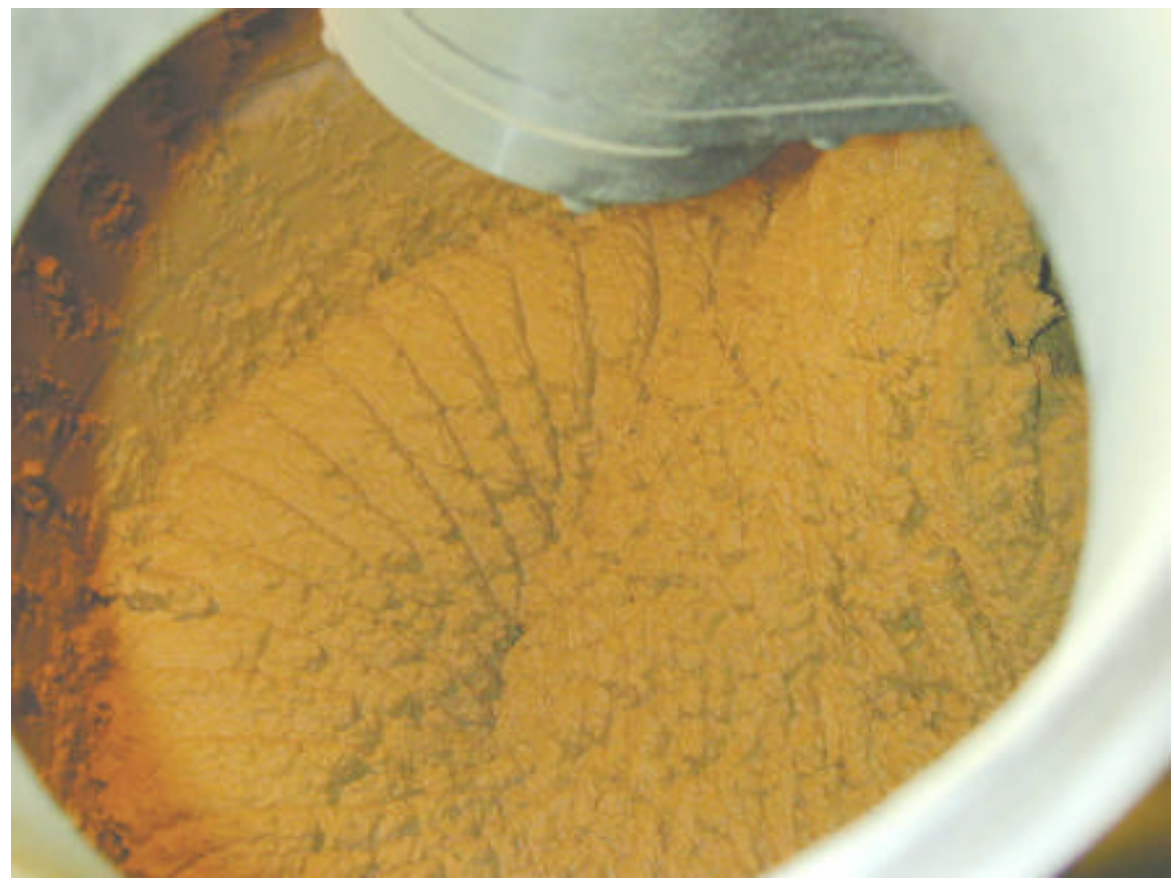

Figure 10 MER04 Sludge With Balance of SPC, After 5 min Mixing. 


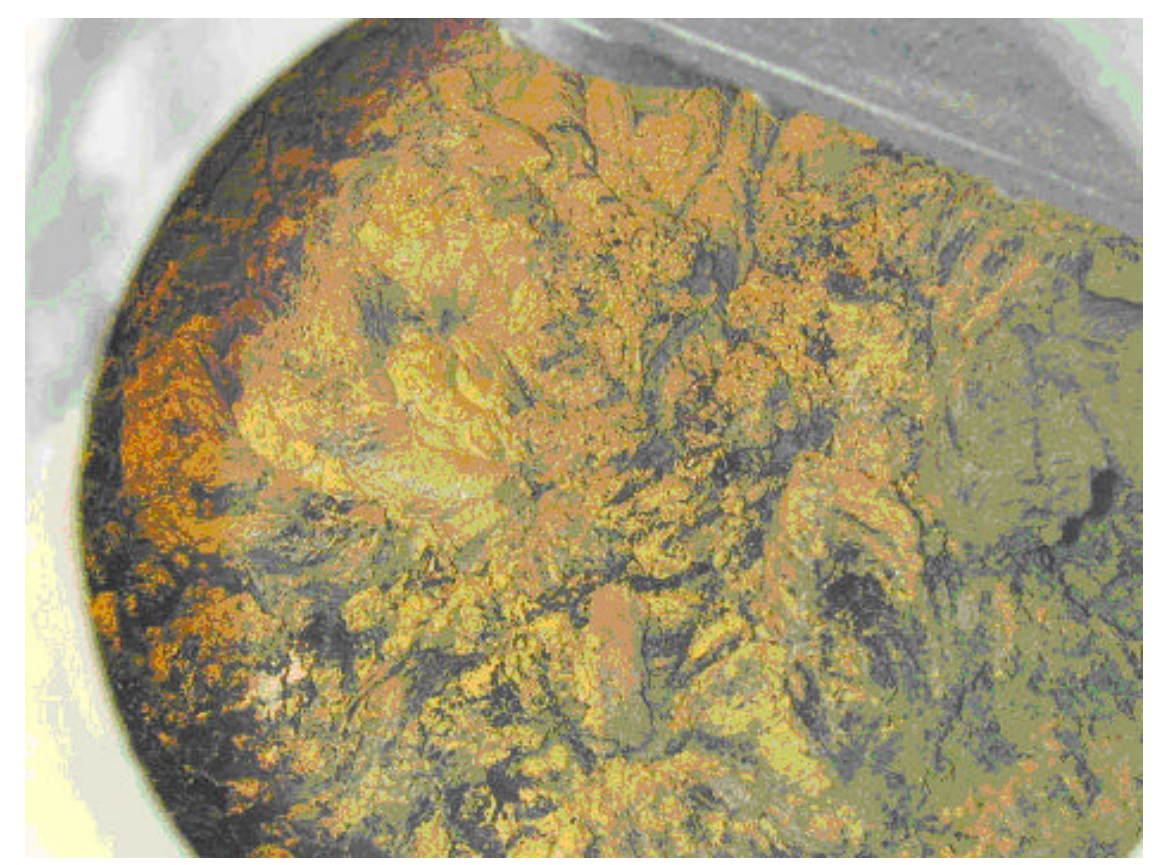

Figure 11 MER04 Sludge/SPC Mixture, After Partial Addition of $\mathrm{Na}_{2} \mathrm{~S}$.

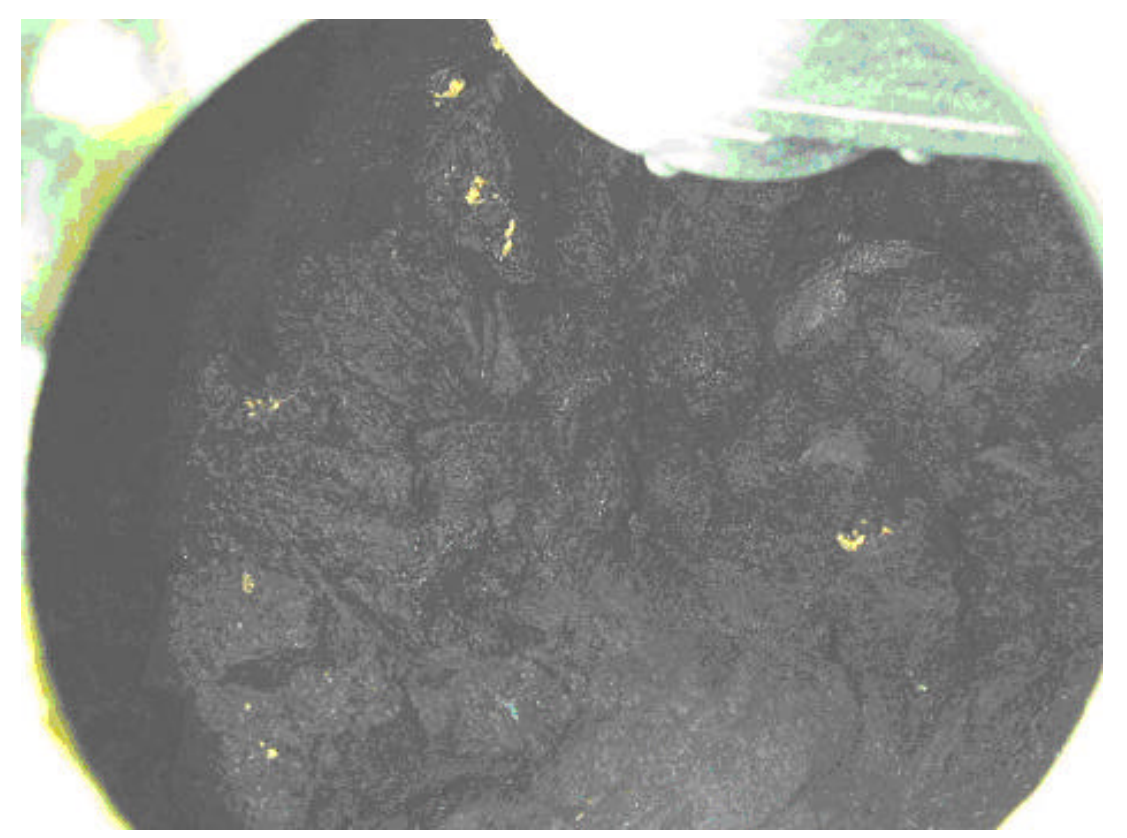

Figure 12 MER04 Sludge/SPC Mixture, After Complete Addition of $\mathrm{Na}_{2} \mathrm{~S}$. 
With the chiller-cooled condensate trap operating and the liquid nitrogen trap filled, the vacuum pump was once again opened to the system and the hot oil setpoint temperatureraised to begin dewatering the sludge. Steady state was achieved after about 90 minutes, with a batch temperature of $115^{\circ} \mathrm{C}$ (slightly below the melting point of SPC, $119^{\circ} \mathrm{C}$ ) and a pressure of $~ 20^{\prime \prime}$ vacuum. It was also at this point that the first sign of condensate was noted in the collection vessel.

For the first process run, the system operated consistently and flawlessly during dewatering of the sludge. System parameters, i.e., vessel temperature, oil bath and setpoint temperature, vessel pressure, screw/orbital drive loads, and condensate levels, were recorded at 30 minute intervals. The batch appearance gradually changed from wet and fluid to a damp, lumpy mixture (Figure 13), then finally to a dry powder (Figure 14). Vessel temperature was consistent throughout the drying phase, varying only between 81.4 and $82.8^{\circ} \mathrm{C}$ however, condensate collection rate ranged from 70 to $530 \mathrm{~mL}$ per 30 minutes, with more inconsistency as the batch became dryer. As the batch dried, a layer of material accumulated at the clearance between the wall and screw, and also in a ring at the top of the screw, perhaps trapping moisture below or behind, or impeding heat transfer to the remainder of the batch. Dewatering continued for 14 hours for the first batch, until the condensate collection rate slowed to zero; approximately $8,250 \mathrm{~mL}$ of liquid was collected in the chiller trap. At this point, the hot oil setpoint was raised to its maximum setting, $185^{\circ} \mathrm{C}$, to quickly melt and discharge the batch. As the vessel temperature increased above $100{ }^{\circ} \mathrm{C}$ however, this ring of apparently dry material above the top of the screw did not melt and fall into the batch, and the material had to be manually pushed into the nowmolten mixture. After this was done, a fairly violent boiling of the molten liquid occurred, along with a significant release of condensate. The melt was discharged after about 30 minutes of mixing, although it was unclear whether all liquid had been released from this newly introduced material. The final condensate volume was approximately $8,780 \mathrm{~mL}$. No appreciable amount of liquid was collected in the liquid nitrogen trap.

The second batch (mercury spiked) was about $11 \mathrm{lb}$ smaller than the first, thus mixing of the SPC, wet sludge, and $\mathrm{Na}_{2} \mathrm{~S}$ was somewhat cleaner, with ess material pulling to the top of the mixer screw. Dewatering of the second batch proceeded smoothly for about 7 hours before a breakdown of the vacuum pump occurred. The pump was replaced however, the replacement pump also failed intermittently, causing variability in the vessel vacuum and subsequent large decreases in the condensation rate. After 17 hours, the system was shut down to locate another pump. To this point, approximately $5,230 \mathrm{~mL}$ of liquid had been collected in the condensate trap, with another $500 \mathrm{~mL}$ collected in the liquid nitrogen trap. Over this period, vessel temperature had ranged from 76.0 to $88.4^{\circ} \mathrm{C}$ (briefly). At shutdown the batch material was granular in consistency, resembling damp sand.

After replacement of the pump, dewatering was resumed, with the new pump reaching a maximum of only $11^{\prime}$ " vacuum. The system was nonetheless operated at a slightly elevated vessel temperature $\left(\sim 90^{\circ} \mathrm{C}\right)$ for another 7 hours, when condensation stopped and the first evidence of melting was observed. A total of $6,600 \mathrm{~mL}$ of liquid had been recovered. At this point, the oil temperature was increased to melt the batch. As less material had accumulated at the top of the screw compared to the first batch, the batch was left undisturbed, and the molten product discharged. 


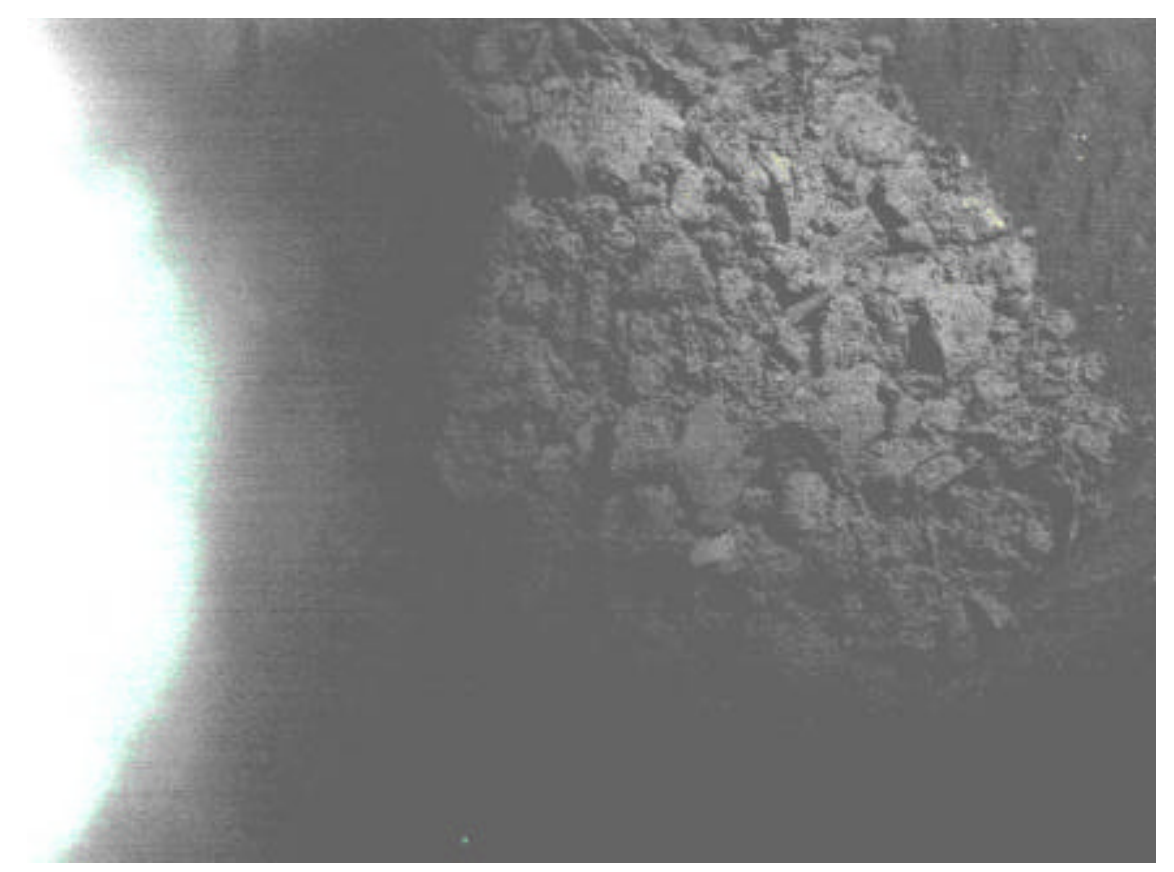

Figure 13 SPSS Reacted MER04 Sludge, After Partial Dewatering.

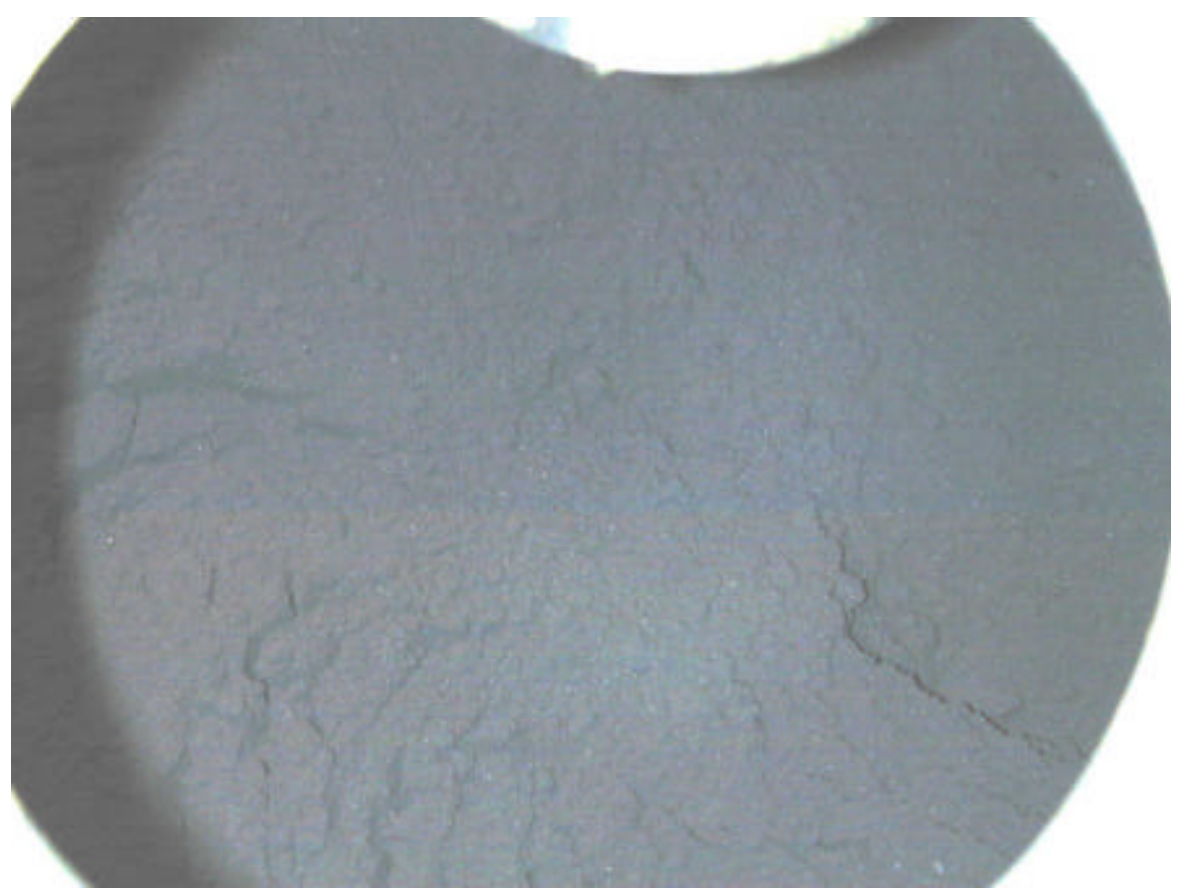

Figure 14 SPSS Reacted MER04 Sludge, After Complete Dewatering. 
Three liter-size jars of material were collected from bottom, middle, and top of the batch for subsequent preparation of TCLP samples. Material was also discharged into 2" diameter thin-wall aluminum tubes, to be cut as cylindrical monoliths. These were also collected at various stages of the batch discharge. Balance of the molten product was collected into a metal shipping pail. Approximate volume of the treated product was 5 gal for each batch.

\subsection{TCLP Qualification of SPSS Processed MER04 Sludge Surrogate Waste}

TCLP samples were made by remelting the subsamples collected from Batch 2. The molten SPSS product was then poured into Teflon molds (Figures 15 and 16) to create small pellets, approximately 8 $\mathrm{mm}(5 / 16$ ") diameter by $8 \mathrm{~mm}(5 / 16$ ") high, which meet the size requirement of the TCLP test while maintaining the integrity of the encapsulated product. Approximately 3,500 gm of sample was pelletized, then combined to form a composite of top, middle, and bottom material from the batch. A sample of this material was shipped to Severn Trent Laboratories (Stamford, CT) for TCLP pre-certification, in accordance with the SOW. Test results, using extraction fluid \#1 ( $\mathrm{pH} \mathrm{4.93"} \mathrm{0.05),} \mathrm{yielded} \mathrm{no} \mathrm{measurable}$ mercury (<10 ppb). ${ }^{7}$ SPSS product cast as 2" diameter cylinders was cut to 2" lengths using a diamond saw. Sixteen pieces $(\sim 3.2 \mathrm{~kg})$, again representing top, middle, and bottom of Batch 2 , were shipped to $\mathrm{UC}$; three pieces $(\sim 0.6 \mathrm{~kg})$ were shipped to ORNL, as called for in the SOW.

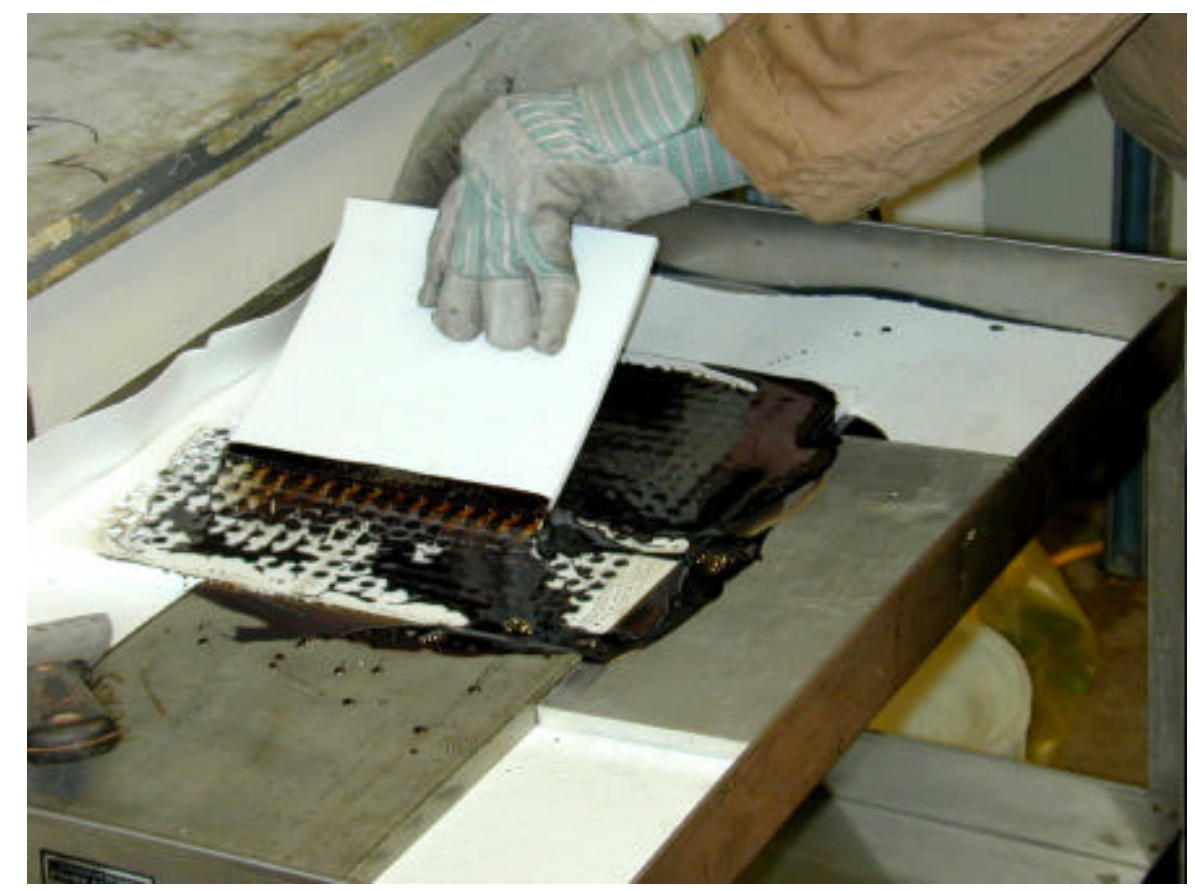

Figure 15 Preparation of TCLP Pellets from SPSS Treated MER04 Sludge. 


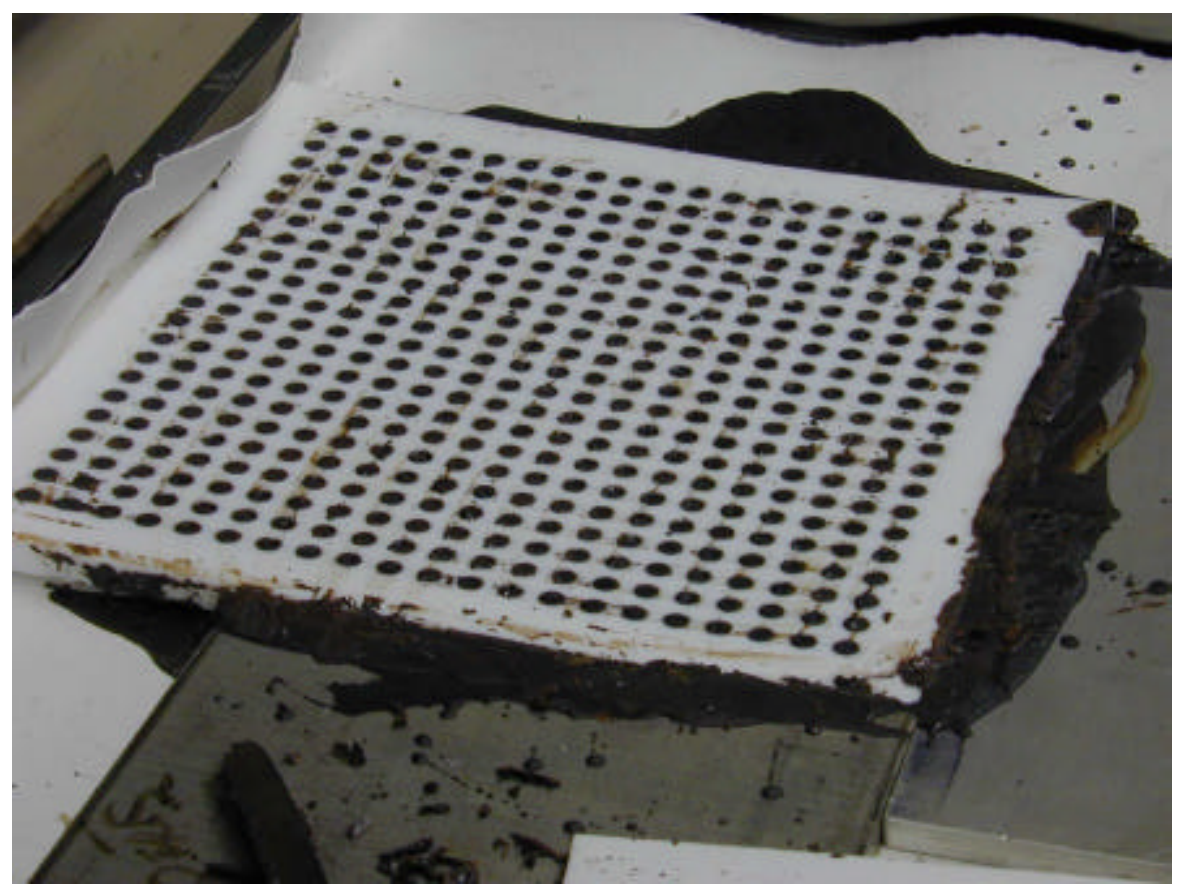

Figure 16 SPSS Treated MER04 Sludge Cast as 8mm Diameter Pellets.

\section{TECHNICAL AND ECONOMIC CONSIDERATIONS}

Other technical and economic considerations associated with application of SPSS to mercurycontaminated sludge treatment include volume changes, mass balance, secondary wastes, and engineering issues.

The SPSS treatment formulation developed for this study yielded a net volume increase. This conclusion is based on data from Batch 1, which had no mercury components. (Losses of materials in Batch 2, during collection of sub-samples to be split between ORNL and UC, and for preparation of monoliths and pellets, made an accurate assessment of volume changes less precise. After melting, Batch 1 decanted into a single 5-gal bucket, with minimal material adhering to the interior surfaces of the Ross dryermixer.) The volume of the surrogate sludge treated was $12.90 \mathrm{~L}(18,444$ grams, density $=1.43 \mathrm{~g} / \mathrm{mL})$. The volume of the final product was $17.6 \mathrm{~L}(31,865 \mathrm{~g}$, density $=1.81 \mathrm{~g} / \mathrm{mL})$. The volume increase observed is $36.4 \%$.

A mass balance is one way of demonstrating that no mercury losses occur during processing. An accurate mass balance would include determination of mercury concentrations in all wastesbefore and after treatment, and in off-gas and condensate collection systems. Unfortunately, resources for mercury analyses in the condensate, HEPA filter, and carbon filter were not allocated for this study. (Samples of these materials will be archived for several months, in case additional resources become available. After 
this, they will be disposed.) In the earlier BNL demonstration of SPSS treatment of elemental mercury and mercury-contaminated soils ${ }^{5}$, a mercury balance demonstrated that only trace quantities of mercury ( $0.3 \%$ ) were volatilized and captured in the off gas collection system.

Secondary wastes can be expected from any treatment process. When the SPSS process is applied to treat mercury-contaminated sludges, secondary wastes fall into two categories: process wastes and incidental wastes, such as PPE. Process wastes include off-gas HEPA filters, activated carbon filter materials, and condensate. A new HEPA filter (8"x8"x4") and new activated carbon material (3 lbs) were installed for this study. Although quantitative estimates of capacity limits have not been determined for these system elements, previous process knowledge indicates that they were not expended to capacity. Quantities of condensate generated were noted earlier. Totalamounts of this secondary waste will depend on the water content of the waste being treated, as well as the total sludge waste (or soil). Incidental wastes include PPE and blotter paper. A total of about 8 cubic feet were generated for this study. PPE waste primarily consisted of disposable PVC gloves, a small volume contribution. The larger amount of incidental waste $(80 \%)$ was blotter paper resulting from the preparation of TCLP pellets. The lab-scale formulation development tests accounted for about one third of the total 8 cubic feet of incidental wastes.

Engineering issues include anticipated operating conditions and throughput, and duty cycle, reliability, and maintainability of the integrated system. Operating conditions and throughput are described in detail in the results section. The system used is based on a pilot-scale 1-cubic-foot mixer-dryer system and issues of process scale-up are beyond the scope of this study. Formulations, process parameters (and subsequently run times), and engineering design were not optimized for this waste stream due to limited resources available for the project.

Reliability and maintenance issues are significant considerations for comparing the viability of commercial systems. Evaluating these issues on the basis of the work described here would be preliminary and beyond the scope of the project. The problems encountered with the vacuum pump were significant but are not attributed to any process-specific conditions. In spite of these apparent limitations, the SPSS application to high mercury content sludges appears promising, because waste forms meeting UTS performance requirements $(<0.025 \mathrm{mg} / \mathrm{L} \mathrm{TCLP} \mathrm{Hg})$ can be produced using commercially available off-the shelf equipment.

The SPSS process was recently licensed for treating elemental mercury waste generated in the mining industry. This large-scale application is expected to provide valuable information on engineering scale-up and issues of reliability, maintenance, and operating conditions for the SPSS process.

\section{DISCUSSION AND CONCLUSIONS}

SPSS is a cost-effective, simple process to treat a wide variety of difficult $\mathrm{Hg}$ streams including elemental mercury, and mercury contaminated soils, sludge, and debris. SPSS can effectively treat elemental mercury at loadings up to $33 \mathrm{wt} \%$, and it meets the current EPA standard of amalgamation for D009 waste containing elemental mixed-waste mercury. Other mercury-contaminated wastes will have 
lower mercury loadings, but may have higher or lower total waste loadings. The total waste loading is limited by both processibility constraints, (e.g., particle size, or other matrix interferences) and final waste form performance (e.g.,leachability).

This study investigated application of SPSS for direct stabilization/solidification treatment of a simulated high mercury subcategory waste, in this case, a sludge waste containing $5000 \mathrm{ppm} \mathrm{Hg}$. Bench-scale treatability tests concluded that maximum waste loading of the dry sludge was limited to $30 \mathrm{wt} \%$, based on physical mixability issues, not the leachability of mercury from the final waste form product. By way of comparison, BNL soil contaminated with similar concentrations of $\mathrm{Hg}$ were successfully treated by SPSS at a total waste loading of $60 \mathrm{wt} \%$. TCLP testing of the SPSS treated MER04 simulated mixedwaste $\mathrm{Hg}$ contaminated sludge yielded a mercury concentration of $<10 \mathrm{ppb}$, below UTS criteria of 25 ppb.

Pilot-scale processing of surrogate sludges was successfully demonstrated, first for a surrogate waste containing no mercury, then for a surrogate containing $5000 \mathrm{ppm}$ mercury. For the non-hazardous batch, mixing and dewatering were very well controlled, recovering approximately $96 \mathrm{wt} \%$ of the added water. For the mercury batch, several vacuum pump shutdowns occurred, likely causing the slightly lower observed yield of condensed vapor of $85 \mathrm{wt} \%$. In both cases, a ring of dried product adhered to the cone mixer wall and did not slump into the melt. This artifact of processing could readily be overcome using an alternate mixer design, one that continuously wipes the wall of the vessel, or by using a smaller batch size. The SPSS treated sludge surrogate successfully met the pre-certification criteria required by the SOW, with a measured TCLP mercury concentration of $<10 \mathrm{ppb}$.

\section{ACKNOWLEDGMENTS}

The authors gratefully acknowledge the assistance of Mike Morris (ORNL) and Greg Hulet (TMFA) in providing guidance and support for this effort. We also thank Catherine Mattus (ORNL) and Linda Reiser (UC) for facilitating shipment of the waste and for their roles in the post-treatment analyses.

\section{REFERENCES}

1 Colombo, P., Kalb, P.D., Heiser, J. H. "Process for the Encapsulation and Stabilization of Radioactive, Hazardous and Mixed Wastes.” U.S. Patent 5,678,234, October 14, 1997.

2 Kalb, P.D., J.H. Heiser, R. Pietrzak, and P. Colombo, "Durability of Incinerator Ash Waste Encapsulated in Modified Sulfur Cement," Presented at the 1991 Incineration Conference: Thermal Treatment of Radioactive, Hazardous, Chemical, Mixed, and Medical Wastes, Knoxville, TN, May 1991.

$3 \quad$ Kalb, P.D., J.H. Heiser, and P. Colombo, "Modified Sulfur Cement Encapsulation of Mixed Waste Contaminated Incinerator Fly Ash," Waste Management, Vol. 11, No. 3, pp. 147-153, Pergamon Press, 1991. 
Kalb, P.D., D. Melamed, M.Fuhrmann, J.W. Adams, M. Sapanara, C. DeTello, "Sulfur Polymer Stabilization/Solidification of Elemental Mercury Mixed Waste," 19th U.S. Department of Energy Low-Level Radioactive Waste Management Conference, Salt Lake City, UT, November 1998.

5 Kalb, P.D., J.W. Adams, and L.W. Milian, "Sulfur Polymer Stabilization/Solidification (SPSS) Treatment of Mixed-Waste Mercury Recovered from Environmental Restoration Activities at BNL,” BNL-52614, January 2001.

6 US Environmental Protection Agency, Toxicity Characteristic Leaching Procedure (TCLP), 40 CFR Part 261, Appendix II, September 19, 1994.

7 Severn Trent Laboratories, Inc., Analytical Draft Report, Project No. COC 10605, Lot \# F1H060124, August 28, 2001. 